\title{
NÂNG CAO CHẤT LƯợNG ĐộI NGŨ GIẢNG VIÊN ĐẠI HỌC GẮN VỚI ĐÀO TẠO THEO CHUẨN AUN-QA ĐÁP ÚNG YÊU CẦU CỦA CUỘC CÁCH MẠNG CÔNG NGHIỆP 4.0
}

\author{
Nguyễn Hoàng Huế(*), Ngô Phạm Toán ${ }^{(* *)}$ \\ (*) Tiến sĩ. Truờng Đại học Thủ Dầu Mọt. Email: huenh@tdmu.edu.vn. \\ (**) Thạc sĩ. Truờng Đại học Thủ Dầu Một.Email: toannp@tdmu.edu.vn
}

DOI: $10.37550 /$ tdmu.CFR/2021.01.140

\section{Tóm tắt}

Cuộc cách mạng công nghiệp lần thứ 4 đang ảnh hương trưc tiếp đến tùng cá thể, gia đình, doanh nghiệp và đặc biệt chịu ảnh hwởng lớn nhất chính là môi truờng giáo dục - nơi trục tiếp đào tạo nguồn nhân lục phục vu cho công nghiệp 4.0. Trong bối cảnh Việt Nam đang hội nhập mạnh mẽ với khu vực và quốc tế, việc xây dựng chuơng trình đào tạo theo chuẩn AUN-QA có một ý nghĩa quan trọng, đáp úng yêu cầu nguồn nhân lực của quá trình hội nhập và phát triển trong bối cảnh cuộc Cách mạng công nghiệp 4.0. Cách mạng này vìa tạo ra nhũ̃ng thời cơ, vì̀a đặt giáo dục đại học Việt Nam trước nhũng thách thức mới diễn ra ngày càng nhanh. Đòi hỏi các cơ sở giáo dục đại học ở Việt Nam phải tiên phong trong nhận thức và hành động của mình để thích ứng với cuộc cách mạng này.Tù việc đánh giá vai trò của đội ngũ và công tác quản lý đội ngũ giảng viên trong truờng đại học hiện nay, tác giả bài viết đã đề xuất nhũng giải pháp nhằm xây dụng đội ngũ giảng viên trong truò̀ng đại học đáp úng yêu cầu đào tạo theo chuẩn AUN-QA đáp úng yêu cầu của cuộc cách mạng công nghiệp 4.0

Từ khóa: $A U N-Q A$, cách mạng công nghiệp 4.0, chất luợng, giảng viên

\section{1. Đặt vấn đề}

Khái niệm cuộc Cách mạng công nghiệp lần thứ 4 (Cách mạng công nghiệp 4.0 $\mathrm{CMCN} 4.0$ ) ngày càng được sử dụng rộng rãi. Khái niệm " $\mathrm{CMCN} 4.0$ " được đề cập lần đầu tiên và cũng là chủ đề của Diễn đàn kinh tế lần thứ 46 tổ chức ngày 20/1/2016 tại thành phố Davos-Klosters, Thụy Sĩ. Tuy vậy, tác động của cuộc CMCN 4.0 đã bắt đầu được "cảm nhận”, đặc biệt là tại các nước phát triển vào những năm cuối thế kỷ XX và đầu thế kỷ XXI. Khác với các cuộc $\mathrm{CMCN}$ trước đây, $\mathrm{CMCN} 4.0$ không gắn với sự ra đời của một công nghệ nào cụ thể mà là kết quả hội tụ của nhiều công nghệ khác nhau, trong đó trọng tâm là công nghệ nano, công nghệ sinh học và công nghệ thông tin - truyền thông.

Chỉ thị số 16/CT-TTG của Thủ tướng Chính Phủ ngày 4/5/2017 về việc tăng cường năng lực tiếp cận cuộc cách mạng công nghiệp lần thứ 4 chỉ rõ: "Cuộc Cách mạng công 
nghiệp lần thứ 4 với xu hương phát triển dựa trên nền tảng tích hợp cao độ của hệ thống kết nối số hóa - vật lý - sinh học với sư đột phá của Internet vạn vật và Trí tuệ nhân tạo đang làm thay đổi căn bản nền sản xuất của thế giới. Cách mạng công nghiệp lần thứ 4 với đặc điểm là tận dụng một cách triệt để súc mạnh lan tỏa của số hóa và công nghệ thông tin. Làn sóng công nghệ mới này đang diễn ra với tốc độ khác nhau tại các quốc gia trên thế giới, nhưng đang tạo ra tác động mạnh mẽ, ngày một gia tăng tới mọi mặt của đời sống kinh tế - xã họi, dẫn đến việc thay đổi phương thức và lực lượng sản xuất của xã hội" [6].

Cách mạng công nghiệp 4.0 làm thay đổi mạnh mẽ phương thức sản xuất và phương pháp quản trị “các nhà máy thông minh", "công sở và thành phố thông minh" được kết nối Internet, liên kết với nhau thành một hệ thống thay vì các dây chuyền sản xuất và phương pháp quản trị hành chính trước đây. Nhờ khả năng kết nối bằng máy tính, các thiết bị di động tiếp cận với các cơ sở dữ liệu lớn từ nhiều nguồn, những tính năng xử lý thông tin được nhân lên nhờ những đột phá về công nghệ bằng trí tuệ nhân tạo, người máy, công nghệ in $3 \mathrm{D}$, công nghệ na-nô, công nghệ điện toán đám mây, công nghệ sinh học, công nghệ lượng tử, công nghệ vật liệu mới,...

Cách mạng công nghiệp 4.0 sẽ mở ra kỷ nguyên mới của sự lựa chọn các phương án đầu tư kinh doanh, tối ưu hóa sử dụng các nguồn lực, thúc đẩy năng suất lao động và hiệu quả, tạo bước đột phá về tốc độ phát triển, phạm vi mức độ tác động làm biến đổi cơ bản hệ thống sản xuất và quản trị xã hội cả chiều rộng lẫn chiều sâu.

AUN (ASEAN University Network) là tổ chức phi chính phủ, phi lợi nhuận được thành lập năm 1995 với mục đích thúc đẩy sự hợp tác và nâng cao chất lượng đào tạo, nghiên cứu, trao đổi giảng viên và sinh viên giữa các trường trong $\mathrm{ASEAN}$.

Khung đảm bảo chất lượng AUN-QA (ASEAN University Network - Quality Assurance) được xây dựng nhằm giúp cải tiến chất lượng giáo dục trong khu vực, hỗ trợ sự lưu động của người học, người lao động và chuyên gia giữa các quốc gia trong khu vực và với quốc tế. Bộ khung được nghiên cứu, xây dựng và cải tiến để đảm bảo các quốc gia có thể áp dụng trong những bối cảnh chính trị, văn hóa và pháp luật khác nhau mà không ảnh hưởng đến những giá trị và truyền thống cốt lõi của từng quốc gia.

AUN-QA là mạng lưới chuyên trách về ĐBCL giáo dục đại học của $A U N$, được thành lập với nhiệm vụ thúc đẩy hoạt động ĐBCL tại các cơ sở giáo dục đại học, nâng cao chất lượng giáo dục đại học và hợp tác với các tổ chức trong khu vực và quốc tế vì lợi ích chung của cộng đồng ASEAN.

Hoạt động đánh giá chất lượng cấp chương trình đào tạo (CTĐT) được AUN-QA triển khai từ năm 2007. Đến nay hơn 160 chương trình đã được đánh giá bởi AUN-QA góp phần đem lại nhiều lợi ích cho các trường đại học là thành viên chính thức và thành viên liên kết của mạng lưới.

Nhằm đáp ứng các thách thức trong cộng đồng chung $\mathrm{ASEAN}$, mạng lưới $\mathrm{AUN}-\mathrm{QA}$ tiên phong thúc đẩy việc hình thành một khung đàm bảo chất lượng (ĐBCL) giáo dục đại học hài hòa cả trong và ngoài $\mathrm{ASEAN}$. Để đạt được mục tiêu này, AUN-QA cần đảm bảo rằng khung $\mathrm{ĐBCL}$ và các tài liệu hướng dẫn được xây dựng phù hợp và mang tính cập nhật. 
Đến nay, đã có phiên bản 3.0 của tài liệu hướng dẫn đánh giá chất lượng cấp chương trình là thành quả của quá trình rà soát, điều chỉnh của nhóm chuyên gia $A U N-Q A$..

Bộ tiêu chuẩn kiểm định chất lượng của Mạng lưới Đại học Đông Nam Á - AUN yêu cầu các Trường Đại học cần phải lấy người học làm trung tâm; xác định chuẩn đầu ra rõ ràng cho từng chương trình cụ thể, sinh viên sau khi ra trường phải nắm được những kỹ năng và kiến thức cần thiết; sự thành công của chương trình đào tạo phải được đánh giá bằng những phản hồi của các bên liên quan, kết quả cuối cùng sẽ được Hội đồng quốc tế kiểm định. Việc kiểm định theo chuẩn $\mathrm{AUN}$ là sự khẳng định về chất lượng sản phẩm đầu ra của chương trình đào tạo trên hệ tham chiếu mang tính quốc tế, tạo điều kiện cho sinh viên tiếp cận công việc một cách dễ dàng, giúp người sử dụng lao động có một cơ sở tin cậy khi tìm kiếm nguồn nhân lực cho mình.

\section{Chất lượng đội ngũ giảng viên đại học gắn với đào tạo theo chuẩn AUN-QA đáp ứng yêu cầu của cuộc cách mạng công nghiệp 4.0}

Giảng viên là chức danh nghề nghiệp của nhà giáo làm công tác giảng dạy ở các trường đại học, cao đẳng. Trên thế giới, nhà giáo đại học thường gắn với một chức vụ khoa bảng hoặc do các trường đại học đề bạt hoặc do Chính phủ bổ nhiệm. Ở Việt Nam, theo quy định của Luật giáo dục 2005, giảng viên đại học (GVĐH) là những nhà giáo làm nhiệm vụ giảng dạy tại các trường đại học, cao đẳng và được phân chia thành các ngạch giảng viên, giảng viên chính, giảng viên cao cấp.

Cách mạng công nghiệp lần thứ 4 với đặc điểm là tận dụng một cách triệt để sức mạnh lan tỏa của số hóa và công nghệ thông tin. Làn sóng công nghệ mới này đang diễn ra với tốc độ khác nhau tại các quốc gia trên thế giới, nhưng đang tạo ra tác động mạnh mẽ, ngày một gia tăng tới mọi mặt của đời sống kinh tế - xã hội, dẫn đến việc thay đổi phương thức và lực lượng sản xuất của xã hội. Cách mạng công nghiệp lần thứ 4 đòi hỏi người lao động Việt Nam phải đáp ứng các yêu cầu: nâng cao trình độ công nghệ, nâng cao năng lực sản xuất và cạnh tranh trong chuỗi sản phẩm; tạo ra sự thay đổi lớn về hình thái kinh doanh dịch vụ; tạo ra nhiều cơ hội cho các doanh nghiệp khởi nghiệp sáng tạo; giảm đáng kể chi phí giao dịch, vận chuyển; tận dụng cơ hội đầu tư hấp dẫn và đầy tiềm năng trong lĩnh vực công nghệ số và Internet đồng thời cũng là cơ hội lớn cho sản xuất công nghiệp với trình độ khoa học và công nghệ tiên tiến.

Tuy nhiên, nếu không bắt kịp nhịp độ phát triển của thế giới và khu vực, Việt Nam sẽ phải đối mặt những thách thức, tác động tiêu cực như: Sự tụt hậu về công nghệ, suy giảm sản xuất, kinh doanh; dư thừa lao động có kỹ năng và trình độ thấp gây phá vỡ thị trường lao động truyền thống, ảnh hưởng tới tình hình kinh tế xã hội đất nước; mất an toàn, an ninh thông tin, xâm phạm bản quyền, thiếu hụt nguồn nhân lực trình độ cao. Mặt khác có khả năng xuất hiện làn sóng đẩy công nghệ lạc hậu từ các nước phát triển sang các nước đang phát triển và chậm phát triển.

Để chủ động nắm bắt cơ hội, đưa ra các giải pháp thiết thực tận dụng tối đa các lợi thế, đồng thời giảm thiểu những tác động tiêu cực của cuộc Cách mạng công nghiệp lần thứ 4 đối với Việt Nam, đỏi hỏi từng cá thể, gia đình, doanh nghiệp và đặc biệt là môi trường 
giáo dục nhất là giáo dục đại học - nơi trực tiếp đào tạo nguồn nhân lực phục vụ cho công nghiệp 4.0 phải đi tiên phong thay đổi mạnh mẽ các chính sách, nội dung, phương pháp giáo dục. Trong đó, vai trò của đội ngũ giảng viên đặc biệt quan trọng.

Để đáp ứng triển khai CTĐT theo chuẩn AUN-QA đáp ứng yêu cầu của cuộc cách mạng công nghiệp 4.0, giảng viên ở bậc đại học phải có những khả năng sau:

- Thiết kế được một chương trình giảng dạy và học tập chặt chẽ, đồng thời thực hiện được chương trình này;

- Áp dụng nhiều phương pháp dạy và học,và chọn lựa phương pháp thích hợp nhất để đạt được kết quả học tập mong đợi;

- Sử dụng và phát triển nhiều loại phương tiện truyền thông trong dạy học;

- Sử dụng nhiều kỹ thuật khác nhau để đánh giá việc học của sinh viên phù hợp với những kết quả học tập dự kiến;

- Tự giám sát và đánh giá việc giảng dạy cũng như chương trình giảng dạy của chính mình;

- Có suy nghĩ, cân nhắc kỹ về việc thực hành giảng dạy của chính mình;

- Xác định các nhu cầu và xây dựng các kế hoạch phát triển liên tục.

- Phải có đủ số lượng giảng viên để thực hiện chương trình đào tạo phù hợp với yêu cầu, xét theo các yêu cầu tổng hợp cả về bằng cấp, kinh nghiệm, khả năng, tuổi tác...

- Việc tuyển chọn và nâng bậc cho giảng viên dựa trên các tiêu chuẩn về năng lực như giảng dạy, nghiên cứu và phục vụ.

- Vai trò và mối quan hệ của các thành viên trong đội ngũ cán bộ được xác định và được mọi người hiểu rõ.

Có triển khai kế hoạch ngắn hạn và dài hạn cho hoạt động phát triển đội ngũ GV (đội ngũ kế thừa, thăng chức, nâng bậc, tái phân công nhiệm vụ, chấm dứt hợp đồng, hưu trí) nhằm đảm bảo số lượng và chất lượng của đội ngũ $\mathrm{GV}$ đáp ứng nhu cầu đào tạo, nghiên cứu và phục vụ cộng đồng.

Nhìn lại chặng đường đã qua, giáo dục đại học nước ta đã phát triển rõ rệt. Đội ngũ giảng viên có trình độ đại học và trên đại học mà tuyệt đại đa số được đào tạo tại các cơ sở giáo dục trong nước đã góp phần quan trọng vào công cuộc đổi mới và xây dựng đất nước. Tuy nhiên, bên cạnh đó cũng còn nhiều hạn chế nhất định đang làm cho những kết quả đạt được chưa đúng với mục tiêu, nhiệm vụ đề ra.

\section{Giải pháp nâng cao chất lượng đội ngũ giảng viên đại học đáp ứng đào tạo theo chuẩn AUN-QA trong bối cảnh cách mạng công nghiệp 4.0}

Chất lượng đội ngũ giảng viên có vai trò quyết định trong việc đảm bảo và nâng cao chất lượng giáo dục. Do vậy, việc phát triển đội ngũ giảng viên được coi là giải phát đột phá trong việc nâng cao chất lượng đào tạo nguồn nhân lực. Để phát triển đội ngũ giảng 
viên đủ về số lượng, đồng bộ về cơ cấu và có chất lượng, trên cơ sở phân tích những vấn đề lý luận và thực trạng đội ngũ giảng viên đại học hiện nay, chúng tôi kiến nghị thực hiện tốt một số giải pháp sau:

Thư nhất, đổi mới công tác xây dựng quy hoạch, kế hoạch và sửa đổi, bổ sung hoàn thiện các quy định về tuyển dụng giảng viên; nghiên cứu xây dựng cơ chế, chính sách đối với giảng viên rõ ràng, theo kịp với thực tế phát triển của nhà trường và xã hội.

Thú hai, xây dựng bộ tiêu chuẩn nghề nghiệp của giảng viên trong trường; đẩy mạnh công tác đào tạo, bồi dưỡng, tự đào tạo và đào tạo lại đối với đội ngũ giảng viên nhằm nâng cao chất lượng của giảng viên cả về năng lực chuyên môn lẫn kiến thức, nghiệp vụ sư phạm;

Thư $b a$, bổ sung, hoàn thiện cơ chế, chính sách đãi ngộ đối với đội ngũ giảng viên tương xứng với thành tích và năng lực cá nhân; điều chỉnh chính sách lương, phụ cấp ưu đãi, cơ chế đãi ngộ phù hợp để cải thiện đời sống vật chất và tinh thần, tạo động lực và điều kiện cho đội ngũ giảng viên nhà trường nâng cao năng lực, trình độ. Đặc biệt là trong điều kiện tuyển sinh hiện nay, cần phải có chính sách sử dụng, điều chuyển và phân công công việc phù hợp để sử dụng đội ngũ giảng viên của trường.

Thú tu: Cần đổi mới phương pháp giảng dạy. Phương pháp giảng dạy từ lâu nay chúng ta vẫn dùng, cho dù có phương tiện máy móc hỗ trợ thì thực chất trong giờ học, người học vẫn ở thế bị động trong nhận thức và tiếp nhận thông tin. Đặc biệt đối với việc phát huy được tính chủ động trong giờ học là một việc hết sức cần thiết.

Thư năm, đẩy mạnh công tác NCKH trong đội ngũ giảng viên, nhất là giảng viên trẻ, gắn $\mathrm{NCKH}$ với đổi mới nội dung, phương pháp giảng dạy; xây dựng nhóm nghiên cứu nhằm tăng cường trao đổi học thuật, sáng kiến kinh nghiệm trong $\mathrm{NCKH}$; tổ chức và khuyến khích giảng viên tham gia hội nghị, hội thảo khoa học trong và ngoài nước nhằm trao đổi kinh nghiệm giảng dạy và $\mathrm{NCKH}$; phải hoàn chỉnh và đổi mới chất lượng quản lý $\mathrm{NCKH}$ trong trường để khuyến khích được đội ngũ giảng viên tham gia nghiên cứu khoa học.

Thú sáu: Đổi mới phương pháp giảng dạy không đòi hỏi chúng ta phải tìm ra một phương pháp nào hoàn toàn mới mẻ, đặc thù mà chính là việc chúng ta nghiên cứu các phương pháp sẵn có, với phương châm giáo dục lấy người học làm trung tâm để lựa chọn cách thức giảng dạy phù hợp nhất. Theo chúng tôi, cần làm tốt những vấn đề sau đây:

- Giảng viên các khoa, bộ môn cần phối hợp các phương pháp giảng dạy khác nhau trong dạy học như diễn giảng, kết hợp với nêu vấn đề, sử dụng tình huống và các phương tiện khoa học kỹ thuật hỗ trợ. Không tuyệt đối hoá phương pháp nào để tránh giảng dạy đơn điệu một phương pháp, nhất là chỉ sử dụng phương pháp diễn dịch, giải thích hoặc lạm dụng phương tiện khoa học, kỹ thuật một cách thái quá dẫn đến sự nhàm chán. Việc sử dụng phương tiện khoa học, kỹ thuật và công nghệ thông tin là cần thiết trong đổi mới phương pháp giảng dạy, tuy nhiên cần phải hiểu rằng không phải sử dụng phương tiện khoa học, kỹ thuật và công nghệ thông tin trong dạy học là đổi mới phương pháp giảng dạy. Cần khai thác triệt để các phương tiện khoa học kỹ thuật phục vụ giảng dạy như sử dụng máy tính để mô hình hóa giáo án, xây dựng biểu đồ, sơ đồ; minh họa bằng hình ảnh; làm video clip các tình huống nghiệp vụ, tình huống có vấn đề, cũng như sưu tầm, biên tập phim minh 
họa cho bài giảng... điều cơ bản là làm tăng khả năng tư duy, sáng tạo của sinh viên là mục tiêu của đổi mới phương pháp giảng dạy

- Tăng cường giảng dạy theo những tình huống có vấn đề, buộc sinh viên phải động não tìm ra phương án để giải quyết các tình huống đó. Quan tâm hướng dẫn sinh viên nghiên cứu tự học và chú ý kiểm tra sự chuẩn bị của sinh viên. Giảng viên thực sự chỉ là người hướng dẫn để sinh viên tư duy, học tập.

- Tăng cường hoạt động đối thoại, hỏi đáp giữa giảng viên và sinh viên trong giảng dạy nhằm khơi dậy tư duy nghiên cứu, tìm tòi và khả năng tự học của sinh viên. Hiện nay nhà trường đã tổ chức nối mạng nội bộ đến từng phòng học, phòng ở của sinh viên. Cho nên, mỗi giảng viên và các khoa, bộ môn cần khai thác triệt để mạng nội bộ để tăng cường trao đổi, đối thoại, giải đáp chuyên môn giữa thầy và trò. Cần xây dựng các hộp thư của Tổ bộ môn, của từng giảng viên để thầy trò trao đổi thông tin, giải đáp thắc mắc và đối thoại với sinh viên về chuyên môn. Hàng ngày, trực ban đơn vị và các tổ của khoa, bộ môn phải thường xuyên mở hộp thư để báo cáo lãnh đạo có thẩm quyền nghiên cứu, giải đáp và đáp ứng yêu cầu của sinh viên. Bảo đảm mạng nội bộ thực sự là phương tiện, cầu nối giữa giảng viên và sinh viên.

Thư bảy, Nhà trường phải đẩy mạnh công tác bồi dưỡng kỹ năng, phương pháp cho giảng viên thông qua sự hỗ trợ huấn luyện của các chuyên gia uy tín trong nước và quốc tế.

\section{Kết luận}

Sau hơn 34 năm đổi mới, giáo dục đại học Việt Nam đã phát triển rõ rệt về quy mô, đa dạng hóa về loại hình và các hình thức đào tạo, bước đầu điều chỉnh cơ cấu hệ thống, cải tiến chương trình, quy trình đào tạo và huy động được nhiều nguồn lực xã hội. Chất lượng giáo dục đại học ở một số ngành, lĩnh vực, cơ sở giáo dục đại học có những chuyển biến tích cực, từng bước đáp ứng yêu cầu phát triển kinh tế - xã hội.

Đào tạo, bồi dưỡng, phát triển nguồn nhân lực chất lượng cao đáp ứng nhu cầu quá trình đẩy mạnh công nghiệp hóa, hiện đại hóa và hội nhập quốc tế là chủ trương, chính sách đúng đắn của Đảng và Nhà nước trong thời gian qua. Để thực hiện được chủ trương, chính sách trên đòi hỏi các cấp, bộ ngành và các cơ sở giáo dục đại học phải coi trọng việc nâng cao chất lượng đội ngũ cán bộ giảng viên.

Để nâng cao chất lượng đội ngũ giảng viên của các trường đại học đáp ứng yêu cầu của cuộc cách mạng công nghiệp 4.0, cần tiến hành đồng bộ nhiều giải pháp như chúng tôi đã kiến nghị ở trên, đòi hỏi sự quyết tâm, đồng lòng của các cấp, bộ ngành và toàn hệ thống trong các cơ sở giáo dục đại học.

\section{Tài liệu tham khảo}

[1] Nguyễn Hữu Châu (chủ biên) (2008), Chất lương giáo dục, những vấn đề lí luận và thực tiễn, NXB Giáo dục. 
[2] Nguyễn Đức Chính (2002), Kiểm định chất lựng trong giáo dục đại học, NXB Đại học Quốc gia Hà Nội.

[3] Nguyễn Cúc (2017), Tác động của cuộc Cách mạng công nghiệp 4.0 đối với cơ sở giáo dục đại học ở Việt Nam và gợi ý chính sách cho Việt Nam, Tạp chí cộng sản, số tháng 8 .

[4] Nguyễn Thị Thu Hương (2012), Xây dưng đội ngũ giảng viên trong trương đại học - Thục trạng và giải pháp, Tạp chí Khoa học ĐHQGHN, Luật học 28 (2012), tr110- 116.

[5] Lê Thị Phương Nam (2012), Thưc trạng và giải pháp nâng cao chất luợng đội ngũ giảng viên đại học giai đoạn 2010-2015, Vụ Văn hóa, Giáo dục, Thanh niên, Thiếu niên và Nhi đồng Quốc hội.

[6] Thủ tướng Chính phủ (2017), Chỉ thị số 16/CT-TTG ngày 4/5/2017 về việc tăng cương năng lục tiếp cận cuộc cách mạng công nghiệp lần thứ 4.

[7] Phan Quang Trung (2017), Giáo dục đại học phải làm gì truớc thách thức của cách mạng công nghiệp 4.0?, Báo điện tử giaoduc.net.vn số ra ngày 22/07/2017.

[8] Trường Đại học Kinh tế Quốc dân (2017), Cuộc Cách mạng Công nghiệp 4.0 và chuyển đổi giáo dục bậc Đại học thế kỷ 21, Kỷ yếu Hội thảo cấp Trường, Hà Nội.

[9] Văn phòng Bộ giáo dục và đào tạo (2019), Số liệu thống kê giáo dục đại học năm học 2017 2018, https://moet.gov.vn/thong-ke/Pages/thong-ko-giao-duc-dai-hoc.aspx?ItemID=5877, ngày truy cập 1/6/2019. 